研究

\title{
超硬合金切削におけるダイヤモンド焼結体の工具摩耗
}

\author{
和田 任弘 \\ 奈良工業高等専門学校機械工学科，广 639-1080大和郡山市矢田町 22.
}

\section{Tool Wear of Polycrystalline Diamond Compacts in Cutting of a Cemented Carbide}

\author{
Tadahiro Wada \\ Department of Mechanical Engineering, Nara National College of Technology, 22 Yata-cho, Yamatokoriyama 639-1080, Japan.
}

Received September 5, 2006

\section{SYNOPSIS}

In a cutting cemented carbide using a polycrystalline diamond compact (PCD) cutting tool, cutting forces, surface roughness and tool wear were experimentally investigated to understand tool machining characteristics. WC-16 mass\% Co was turned with the various kinds of PCD cutting tools that had different diamond particle sizes and different diamond contents. The following results were obtained: (1) The wear of PCD cutting tool with rake angle $0^{\circ}$ was slower than that with $-6^{\circ}$. (2) The tool wear decreased with increase of the diamond particle size. (3) In case of short cutting distance, the surface roughness decreased with decrease of the diamond particle size. However, when the tool wear was larger, the surface roughness increased with decrease of the diamond particle size.

As mention above, it was considered that a PCD with both the rake angle $0^{\circ}$ and the diamond particle size $30 \mu \mathrm{m}$ was the most effective tool material in cutting of $\mathrm{WC}-16 \mathrm{mass} \% \mathrm{Co}$ from the standpoint of the surface roughness and the tool wear.

\section{KEY WORDS}

cutting, polycrystalline diamond compact, cemented carbide, tool wear, surface roughness

\section{1 緒言}

超硬合金は切削工具用材料として開発されたものである" が，高硬度，高圧縮強度など優れた諸特性を有するため，耐 摩耗性が要求される機械部品や圧延ロールなど切削工具以外 の用途にも多く使用されている，このような超硬合金部品の 最終工程の多くは研削が行われている．このため，研削に費 やす時間が多大となり非能率的であるだけでなく, 生産コス トが高くなるという問題点が生じている22. 超硬合金の切削に 関する研究は, 古くから行われており, 工具材としてダイヤ モンド焼結体 (以下, PCD: Polycrystalline Diamond Compact)が 適している ${ }^{3)}$. PCD はダイヤモンド粒径やダイヤモンド含有 量によって機械的性質が異なるため，被削材に適したPCD工 具を選択する必要がある4)。このため, PCD 工具で超硬合金 を切削する場合，ダイヤモンド粒径やダイヤモンド含有量を 変化させた PCD工具で超硬合金の切削を行い, 超硬合金切削 に適したPCD工具を選択する必要がある。

そこで本研究では, ダイヤモンド粒径の異なるPCD工具で
超硬合金を乾式切削し, 切削抵抗, 表面粗さおよび工具摩耗 を調べた結果について報告する。

\section{2 実験方法}

被削材にはWC-16mass\%Co 超硬合金を用いた. Table 1 に 物性值を示す。超硬合金の密度は $14.0 \mathrm{Mg} / \mathrm{m}^{3}$, 硬さはHRA87 である。

切削工具には工具形状の異なる2種類のバイト(すくい角が $0^{\circ}$ と-6 $)$ を用いた. すなわち, $\square 16 \mathrm{~mm} \times 16 \mathrm{~mm}$ バイトホル ダに, TCGW16T308型チップを取付けたバイトで, この場合 の工具形状は $\left(0^{\circ}, 0^{\circ}, 7^{\circ}, 7^{\circ}, 29^{\circ},-1^{\circ}, 0.8 \mathrm{~mm}\right)$ となり, すくい 角が $0 \circ$ である。もう一つは， $\square 25 \mathrm{~mm} \times 25 \mathrm{~mm}$ バイトホルダ に，TNGA160408 型チップを取付けたバイトで，この場合の 工具形状は $\left(-6^{\circ},-6^{\circ}, 6^{\circ}, 6^{\circ}, 29^{\circ},-1^{\circ}, 0.8 \mathrm{~mm}\right)$ となり, すくい 角がー $6^{\circ}$ である. なお, ここで, 7つの数字は, 前から順に前 すくい角, 横すくい角, 前逃げ角, 横逃げ角, 前切刃角, 横 切刃角, ノーズ半径である. また, 工具切れ刃は, 市販のま 
Table 1 Characteristic values of WC-16mass\% Co work piece.

\begin{tabular}{cccccc}
\hline Density & Hardness & T.R.S. & $\begin{array}{c}\text { Compressive } \\
\text { strength } \\
(\mathrm{GPa})\end{array}$ & $\begin{array}{c}\text { Young's } \\
\text { modulus } \\
(\mathrm{GPa})\end{array}$ & $\begin{array}{c}\text { Thermal } \\
\text { conductivity } \\
(\mathrm{W} /(\mathrm{m} \cdot \mathrm{K}))\end{array}$ \\
\hline 14.0 & 87.0 & 3.3 & 4.0 & 520 & 82 \\
\hline
\end{tabular}

T.R.S.: Transverse Rupture Strength

Table 2 Particle size and diamond content of Polycrystalline Diamond Compacts (PCDs).

\begin{tabular}{lcccc}
\hline & PCD & PCD & PCD & PCD \\
& A & B & C & D \\
\hline $\begin{array}{l}\text { Particle size } \\
(\mu \mathrm{m})\end{array}$ & 4.5 & 12.5 & 28 & 45 \\
\hline $\begin{array}{l}\text { D.C. } \\
(\text { Vol.\% })\end{array}$ & 88.0 & 91.0 & 94.0 & 96.5 \\
\hline
\end{tabular}

D.C.: Diamond content

Table 3 Cutting conditions of WC-16mass\% Co by various PCDs.

\begin{tabular}{lll}
\hline Cutting speed & $\mathrm{V}(\mathrm{m} / \mathrm{s})$ & 0.25, \\
& & $0.15 \sim 0.37^{*}$ \\
\hline Feed rate $\mathrm{S}(\mathrm{mm} / \mathrm{rev})$ & 0.015, \\
& & $0.05^{*}$ \\
\hline \multirow{2}{*}{ Depth of cut a $(\mathrm{mm})$} & 0.1, \\
& $0.2^{*}$ \\
\hline Cutting method & Dry \\
\hline
\end{tabular}

* : Face turning

まの状態で使用した.

工具材はダイヤモンド粒径の異なる4種類の PCD を使用し た. 使用したPCDのダイヤモンド粒径とダイヤモンド含有量 を Table 2 に示す.なお, 2 種類のバイトいずれについてもこ れら 4 種類の PCD を準備した.

使用旋盤は, 無段変速装置付き高速精密旋盤である. Table 3 に示す切削条件で超硬合金の外周旋削 (一部, 端面切削)を乾 式で行い, 切削抵抗, 表面粗さおよび工具摩耗を調べた。端 面切削の場合, 内径 $40 \mathrm{~mm}$, 外径 $100 \mathrm{~mm}$, 厚さ $20 \mathrm{~mm}$ の円板 状の被削材を内径部から外径部に向かって切削を行った。こ のため, 切削速度は内径部で $0.15 \mathrm{~m} / \mathrm{s}$, 外径部で $0.37 \mathrm{~m} / \mathrm{s}$, 平 均の切削速度 $\mathrm{Vm}$ は $0.25 \mathrm{~m} / \mathrm{s}$ である. 切削抵抗は, 共和電業社 製TD型工具動力計, 動的ひずみ測定器にて測定し,レコーダ に記録させた．表面粗さの測定には，東京精密社製サーフコ ム $1800 \mathrm{~A}$ 型触針式表面粗さ測定器を用い, 送り方向の仕上げ 面のプロフィールを記録した。

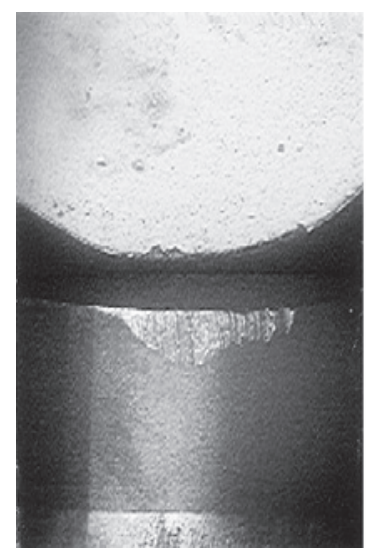

(a) TNGA $(\mathrm{L}=0.7 \mathrm{~km})$ $\mathrm{V}=0.25 \mathrm{~m} / \mathrm{s}, \mathrm{S}=0.015 \mathrm{~mm} / \mathrm{rev}, \mathrm{a}=0.1 \mathrm{~mm}$,

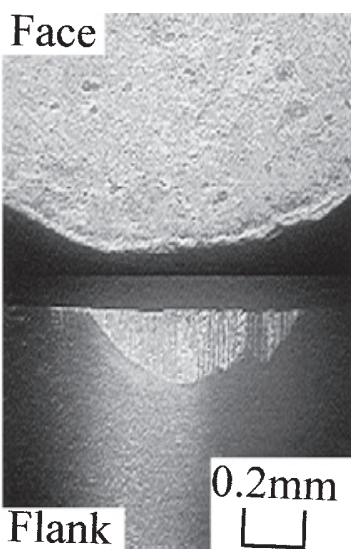

(b) TCGW

$(\mathrm{L}=1.1 \mathrm{~km})$
Fig.1 Tool wear of PCD B with (a) TNGA: Rake angle $-6^{\circ}$ and (b) TCGW: Rake angle $0^{\circ}$ in cutting of WC-16 mass $\% \mathrm{Co}$ (L: Cutting distance).

\section{3 実験結果および考察}

\section{1 工具摩耗}

工具形状, すなわちすくい角の異なる 2 種類の PCD 工具で 超硬合金を外周旋削し, 工具摩耗を調べた. Fig.1 に PCD工具 の摩耗状態を示す.なお, L は切削距離, 工具材はPCD B で ある.いずれの工具形状の PCD 工具においても, すくい面に 比べ，逃げ面が主な工具損傷となっている.

次に, 工具形状の異なる 2 種類の PCD 工具について, 逃げ 面摩耗幅の最大值 VBmax と切削距離 Lの関係を調べ, その結 果を Fig. 2 に示す. 工具形状 TCGW の摩耗進行は, 工具形状 TNGAに比べやや遅い。これは，すくい角の違いによるもの と考えられるので切削抵抗を調べた. Fig.3に, 切削面積あた りの切削 3 分力を示す. ここで, (切削面積 $)=($ 切込み $) \times($ 送 り)とした. Fig.3に示すように工具形状 TCGW の切削面積あ たりの切削 3 分力, すなわち主分力 $\mathrm{fc}$, 背分力 $\mathrm{ft}$, 送り分力 $\mathrm{ff}$ は，工具形状 TNGAに比べ小さい，このことから，工具形状 TCGW の PCD 工具で超硬合金を切削した場合, 切削 3 分力が 小さくなり摩耗進行がやや遅くなったと考えられる.なお, 超硬合金切削においては, 背分力 $\mathrm{ft}$ が主分力 $\mathrm{fc}$ に比べ大きく なる. また，切削面積あたりの切削 3 分力，たとえば主分力 


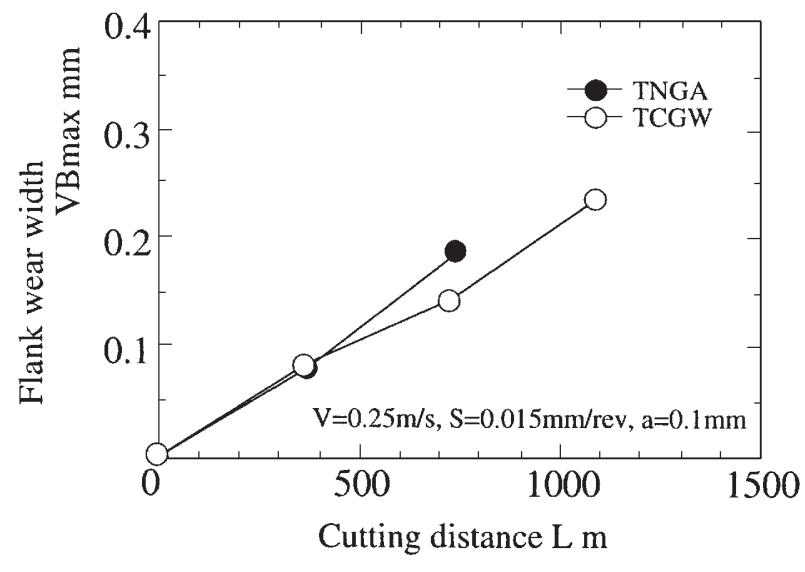

Fig.2 Relation between cutting distance and flank wear width of PCD B (TNGA: Rake angle $-6^{\circ}$, TCGW: Rake angle $0^{\circ}, \mathrm{V}$ : Cutting speed, S: Feed rate, a: Depth of cut).

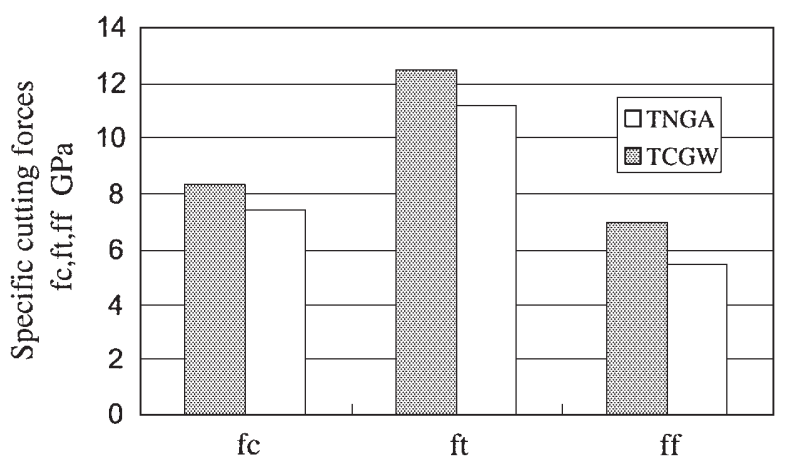

Fig.3 Specific cutting forces of PCD B in cutting of WC-16mass\% Co (TNGA: Rake angle $-6^{\circ}$, TCGW: Rake angle $0^{\circ}$, fc: Principal force, ft: Thrust force, ff: Feed force).

の場合, $\mathrm{fc}$ は $8 \mathrm{GPa}$ となり, 金属切削の場合に比べかなり大き くなるのが特徵であると考えられる.

以上のことから, 工具形状の異なる 2 種類の PCD 工具で超 硬合金を乾式切削すると, 工具形状 TCGWのPCD工具の方が 摩耗進行は遅かった. そこで, 工具形状TCGWのPCD工具に おいて，ダイヤモンド粒径の異なるPCD工具で超硬合金を外 周旋削し, 工具摩耗を調べた. Fig.4にPCD工具の摩耗状態を 示す。なお， L沏削距離である. 4 種の PCD 工具において も，逃げ面が主な工具損傷となっている.

Fig.5 に逃げ面摩耗幅の最大值 VBmax と切削距離 L の関係 を示す.ダイヤモンド粒径の大きいPCD D の摩耗進行が最も 遅い.このことから,ダイヤモンド粒径が大きくなるほど, 摩 耗進行が遅くなることが分かる，そこで，この理由を調べる ために，PCDの機械的性質を調べた，その結果をTable 4 に示 す。硬さ測定にはマイクロヌープ硬さ試験機を使用した。測 定条件は, 測定荷重 $5 \mathrm{~N}$, 測定荷重保持時間 $15 \mathrm{~s}$ である. なお, ビッカース硬さ表示が一般的なため, ヌープ硬さをビッカー ス硬さに換算して示した.この Table 4より, ダイヤモンド粒

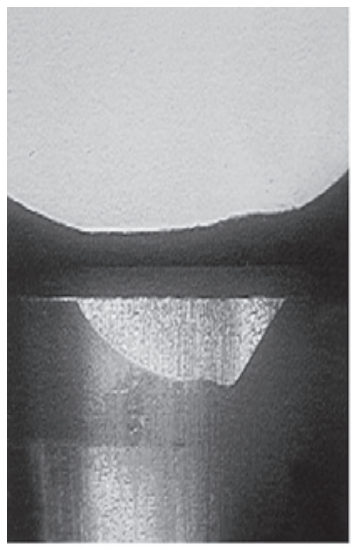

(a) PCD A

$(\mathrm{L}=0.8 \mathrm{~km})$

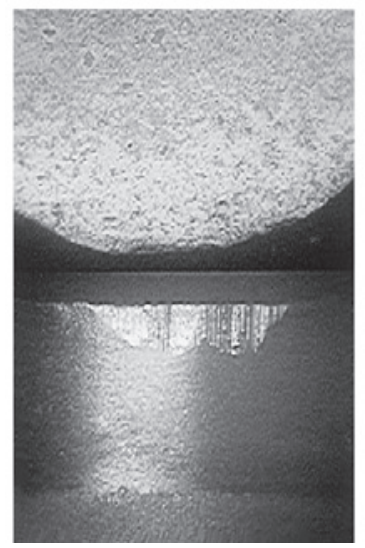

(c) PCD C

$(\mathrm{L}=1.1 \mathrm{~km})$

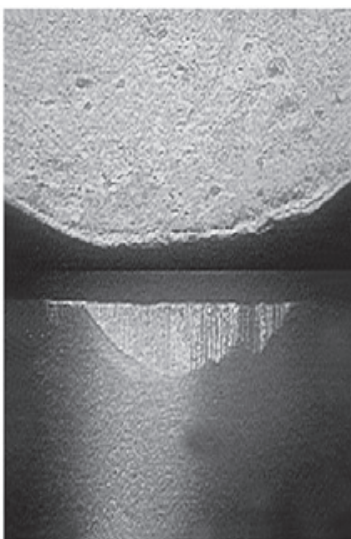

(b) PCD B $(\mathrm{L}=1.1 \mathrm{~km})$

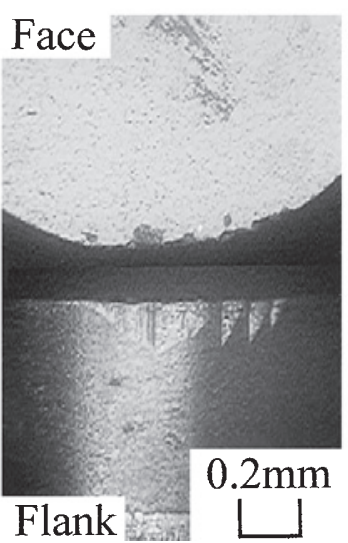

(d) PCD D

$(\mathrm{L}=1.5 \mathrm{~km})$
$\mathrm{V}=0.25 \mathrm{~m} / \mathrm{s}, \mathrm{S}=0.015 \mathrm{~mm} / \mathrm{rev}, \mathrm{a}=0.1 \mathrm{~mm}$

Fig.4 Tool wear of (a) PCD A, (b) PCD B, (c) PCD C and (d) PCD $\mathrm{D}$ in cutting of WC-16mass\% Co (L: Cutting distance, V: Cutting speed, S: Feed rate, a: Depth of cut).

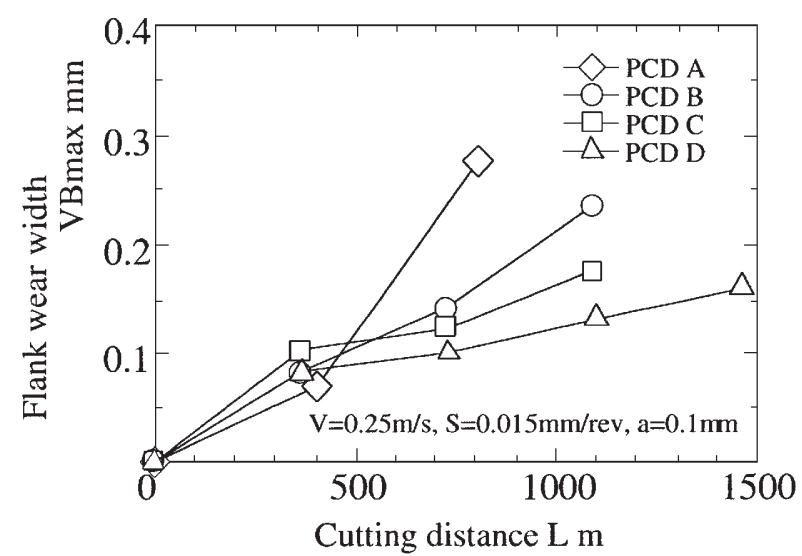

Fig.5 Relation between cutting distance and flank wear width of various PCDs in cutting of WC-16 mass\% Co (V: Cutting speed, S: Feed rate, a: Depth of cut). 
Table 4 Mechanical properties of PCDs.

\begin{tabular}{lcccc}
\hline & PCD & PCD & PCD & PCD \\
A & C & D \\
\hline $\begin{array}{l}\text { Hardness } \\
\text { (HV) }\end{array}$ & 9000 & 10000 & 11000 & 12000 \\
\hline $\begin{array}{l}\text { T.R.S } \\
\text { (GPa) }\end{array}$ & 1.8 & 1.7 & 1.6 & 1.5 \\
\hline
\end{tabular}

T.R.S.: Transverse Rupture Strength

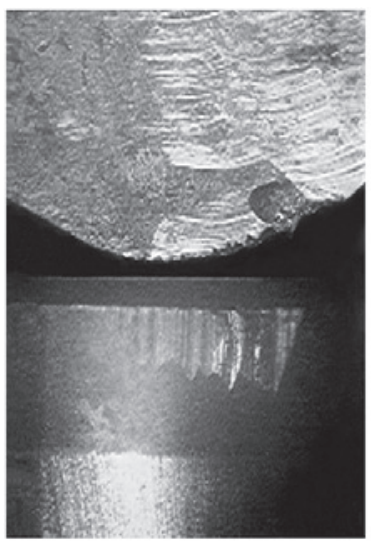

(a) PCD A

$(\mathrm{L}=130 \mathrm{~m})$

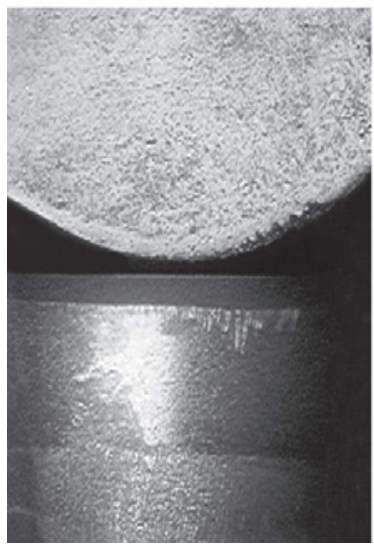

(c) PCD C

$(\mathrm{L}=130 \mathrm{~m})$

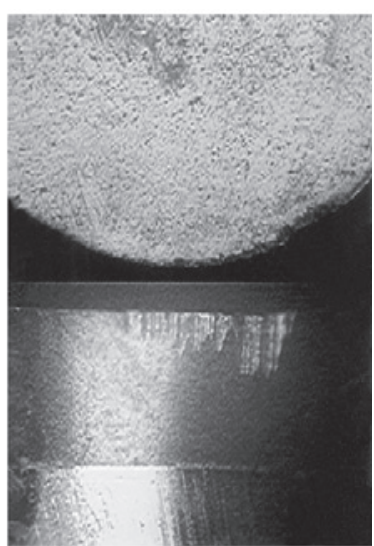

(b) PCD B $(\mathrm{L}=130 \mathrm{~m})$

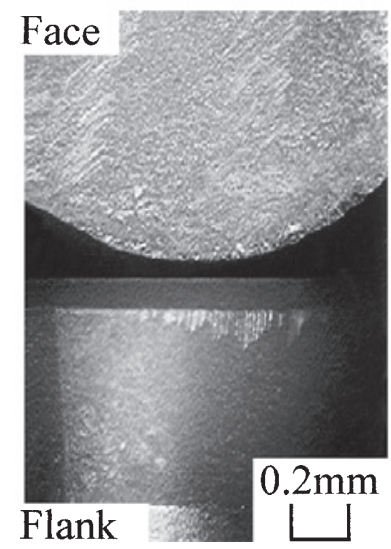

(d) PCD D

( $\mathrm{L}=130 \mathrm{~m})$
$\mathrm{Vm}=0.25 \mathrm{~m} / \mathrm{s}, \mathrm{S}=0.05 \mathrm{~mm} / \mathrm{rev}, \mathrm{a}=0.2 \mathrm{~mm}$

Fig.6 Tool wear of (a) PCD A, (b) PCD B, (c) PCD C and (d) PCD $\mathrm{D}$ in face turning of WC-16 mass\% Co (L: Cutting distance, $\mathrm{Vm}$ : Mean value of cutting speed, S: Feed rate, a: Depth of cut).

径の増加につれて, 抗折力は低下しているが, 硬さは増加し ている.これは，Table 2に示したようにダイヤモンド粒径の 大きい工具ほどダイヤモンドの含有量が高くなるので, 工具

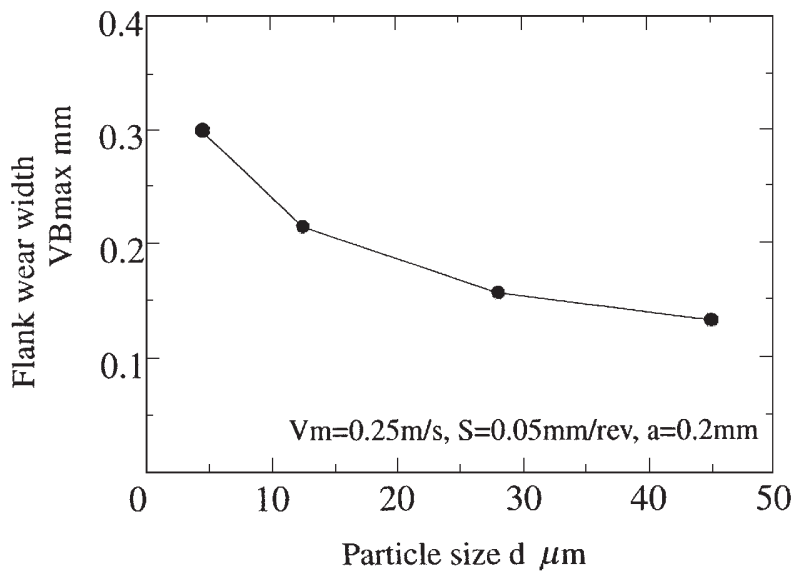

Fig.7 Relation between particle size and flank wear width in face turning of WC-16mass\% Co at cutting distance $130 \mathrm{~m}$ (Vm: Mean value of cutting speed, S: Feed rate, a: Depth of cut).

の硬さが上昇するためである.したがって，ダイヤモンド粒 径が大きくなるにつれて, 工具の硬さが上昇し, 摩耗進行が 遅くなったと考えられる。

3.2 表面粗さ

上述のことから, WC-16mass\% Co 超硬合金を PCD 工具で 切削する場合，すくい角は-6゚よりも $0^{\circ}$ の方が適しており， さらにダイヤモンド粒径の大きいPCD工具が適していること が分かった. 次に, ダイヤモンド粒径の異なるPCD工具で超 硬合金の端面切削を行い工具の摩耗を調べた.

Fig.6に工具の摩耗状態を示す.なお, 切削距離 L は $130 \mathrm{~m}$ の場合である. 4 種の PCD 工具においても，逃げ面が主な工 具損傷となっている.

Fig.7に逃げ面摩耗幅の最大値とダイヤモンド粒径の関係を 示す. なお, 切削距離は $130 \mathrm{~m}$ の場合である. ダイヤモンド 粒径の大きい工具材 PCD Dの工具摩耗が最も小さい.このこ とから, 端面切削においてもダイヤモンド粒径が大きくなる ほど, 工具摩耗が小さくなることが確認できた.

次に, PCD工具のダイヤモンド粒径が被削材の表面粗さに 及ぼす影響を調べた. Fig.8に被削材の送り方向の断面曲線を 示す. 工具材はPCD Cの場合を示す. なお, 図中の S, M, Eは 表面粗さの測定箇所を示し, $\mathrm{S}$ 部は被削材の内径部付近, M部 は中心部付近, E部は外径部付近である. 図中の断面曲線より 下側が，被削材超硬合金である．切削の進行に連れ工具は摩 耗するが，(a)，(b)，(c)にそれぞれ示すように切削が進行して も, 送り $0.05 \mathrm{~mm}$ をピッチとする送りマークが見られ, 送り 方向の断面曲線に大きな変化は見られない.

Fig.9に表面粗さとダイヤモンド粒径の関係を表す.この図 より, 工具摩耗が小さい $S$ 部, $M$ 部においてはダイヤモンド 粒径の小さい工具の方が表面粗さも小さい. しかし, ダイヤ モンド粒径の小さい工具では, 切削が進行し, 工具摩耗が大 きくなると, 表面粗さも大きくなる.なお, PCD AおよびPCD 


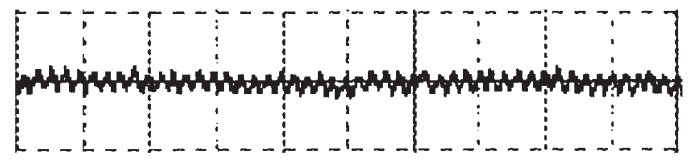

(a) $\mathrm{S}(\mathrm{Ra} 0.178 \mu \mathrm{m}, \operatorname{Ry} 0.918 \mu \mathrm{m})$

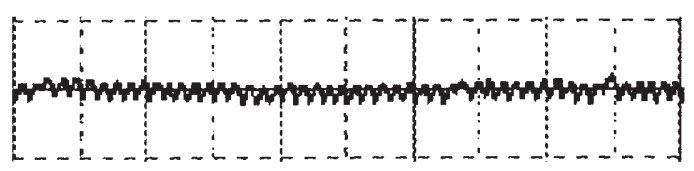

(b) $\mathrm{M}(\mathrm{Ra} 0.191 \mu \mathrm{m}, \mathrm{Ry} 0.891 \mu \mathrm{m})$

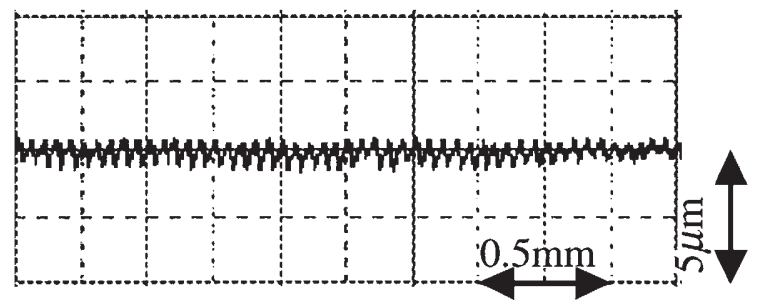

(c) E $(\operatorname{Ra} 0.185 \mu \mathrm{m}$, Ry $0.901 \mu \mathrm{m})$

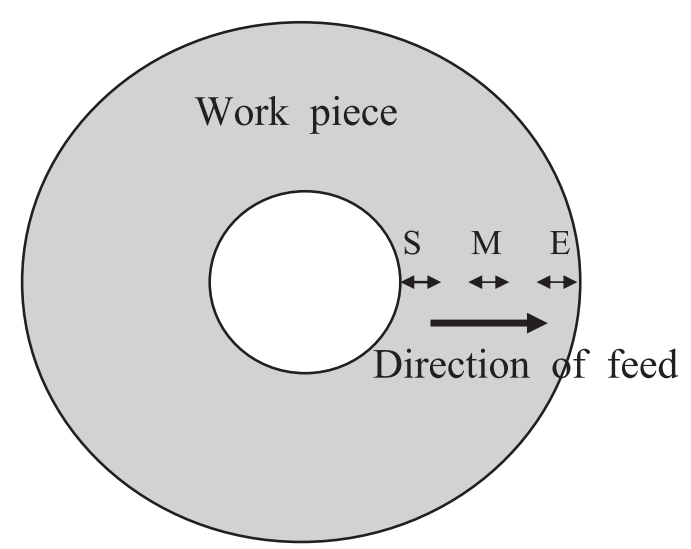

$\mathrm{Vm}=0.25 \mathrm{~m} / \mathrm{s}, \mathrm{S}=0.05 \mathrm{~mm} / \mathrm{rev}, \mathrm{a}=0.2 \mathrm{~mm}$

Fig.8 Surface profile curve of PCD C in face turning of WC-16 mass\% Co (Ra: Average surface roughness, Ry; Maximum height, Vm: Mean value of cutting speed, S: Feed rate, a: Depth of cut).

B では, PCD 工具の移動距離が $30 \mathrm{~mm}$ ( 切削距離 $130 \mathrm{~m}$ ) で表 面粗さが大きくなっている.これは, Fig.7に示したように工 具摩耗が増大するためである.このことから, PCD 工具の寿 命を延長させる方法が必要と考えられる. PCD工具の寿命を 延長させる方法として, ダイヤモンドは, 常温では非常に高 硬度であるが, $400^{\circ} \mathrm{C}$ から硬さが急激に低下する ${ }^{5}$. さらに, $700^{\circ} \mathrm{C}$ から酸化し始める®. このため, 湿式で切削を行うこと が有効な方法であると考えられる.

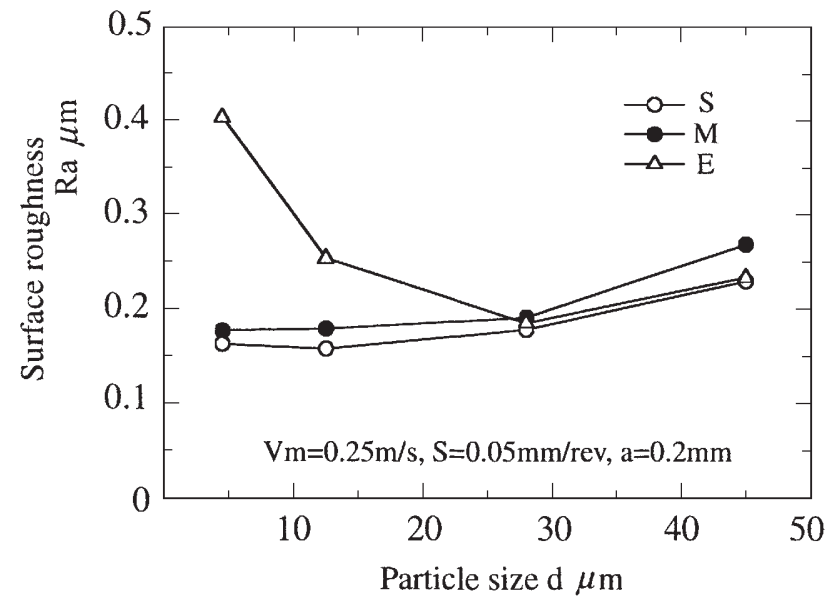

Fig.9 Relation between particle size and surface roughness in face turning of WC-16mass\% Co (Ra: Average surface roughness, Vm: Mean value of cutting speed, S: Feed rate, a: Depth of cut).

\section{4 結 言}

WC-16mass\%Co 超硬合金を, 工具形状の異なる2種の PCD 工具(すくい角 $0^{\circ},-6^{\circ}$ ), ダイヤモンド粒径の異なる 4 種のPCD 工具 (粒径 $4.5 \mu \mathrm{m} \sim 45 \mu \mathrm{m}$ ) で乾式切削し, 切削抵抗, 表面粗 さ, 工具摩耗を調べた.

得られた主な結果は次の通りである.

(1) すくい角 $0^{\circ}$ のCD工具の切削抵抗は, すくい角 $-6^{\circ}$ の PCD 工具に比べ小さかった.

(2) すくい角 $0^{\circ}$ のCD工具の摩耗進行は, すくい角 $-6^{\circ}$ のCD 工具に比べ遅かった.

(3) PCD 工具の摩耗進行は, ダイヤモンド粒径が大きいほど 遅かった。

(4) 表面粗さは, 工具摩耗が少ない切削初期では, ダイヤモン ド粒径の小さいPCD 工具の方が小さかった. しかし, 切 削の進行に連れ工具摩耗が大きくなると,ダイヤモンド粒 径の小さい切削工具の方が表面粗さは大きくなった.

以上のことから, 超硬合金を PCD 工具で切削する場合, す くい角が大きい方が工具の摩耗進行がやや遅くなる.また, ダイヤモンド粒径を小さくすると, 切削初期の表面粗さは小 さくなるが, 切削が進行し摩耗が大きくなると, 表面粗さは 大きくなる、このため, ダイヤモンド粒径については, 表面 粗さおよび工具摩耗の点で最適な粒径が存在し, 本実験の範 囲内では, ダイヤモンド粒径 $30 \mu \mathrm{m}$ の PCD 工具が最適と考え られた。

\section{謝辞}

被削材超硬合金をご提供いただきました三菱マテリアル梸 に深く感謝の意を表します。

\section{文献}

1) K.Karino: Nannsakuzai, Sinnsozai no Sessakukakou 
Hanndobukku, Kougyoutyousakai, (2002) 375

2) S.J.Heo, T.Miyamoto, S.Hanasaki and J.Fujiwara: "Study on Cutting of Cemented Carbide", J. Jpn. Soc. Precision Engineering, 69(2003) 1724-1728.

3) H.Kiso, M.Suzuki and T.Taguchi: "Turning of High Hardness Materials", Tungaloy, (1986)9-23.

4) T.Wada, J.Fujiwara and H.Koizumi: "Wear Characteristics of
Diamond Tool in Cutting of Al-17 mass\% Si Alloy", Proceedings of The $1^{\text {st }}$ International Con. on Design Engineering and Science, Vienna, Jpn. Soc. Design Engineering, (2005) 181-185.

5) Daiyamondo kougyou Kyoukai: Daiyamondo Kougu Manyuaru, Kogyo Chosakai Publishing, (1979) 33.

6) Daiyamondo kougyou Kyoukai: Daiyamondo Kougu Manyuaru, Kogyo Chosakai Publishing, (1979) 34. 